Article

\title{
Study on the Effect of Extraneous Moisture on the Spontaneous Combustion of Coal and Its Mechanism of Action
}

\author{
Yuguo $\mathrm{Wu}^{1,2}$, Yulong Zhang ${ }^{1,2, *}$, Jie Wang ${ }^{1}$, Xiaoyu Zhang ${ }^{1}$, Junfeng Wang ${ }^{2}$ and \\ Chunshan Zhou ${ }^{1,2}$ \\ 1 College of Safety and Emergency Management Engineering, Taiyuan University of Technology, \\ Taiyuan 030024, China; wuyuguo@tyut.edu.cn (Y.W.); wangjie@tyut.edu.cn (J.W.); tyutky@126.com (X.Z.); \\ zhouchunshan@tyut.edu.cn (C.Z.) \\ 2 Shanxi Engineering Research Center for Mine Ventilation and Fire Prevention, Taiyuan 030024, China; \\ wangjunfeng@tyut.edu.cn \\ * Correspondence: zhangyulong@tyut.edu.cn; Tel.: +86-351-6187815
}

Received: 3 February 2020; Accepted: 11 March 2020; Published: 16 April 2020

\begin{abstract}
It is imperative to have an in-depth understanding of the effect of extraneous moisture on the spontaneous combustion of coal not only for the control and prevention of coal spontaneous combustion in the coal mining industry, but also for the optimization design and application of the technological process. In this study, the type of moisture in a coal body has been redefined for the first time from the perspective of disaster prevention and control, i.e., original occurrence of moisture in the coal matrix and the extraneous moisture from the technological process. A suit of coal bodies with different extraneous moisture was prepared by soaking long-flame coal with a low water content. Using a temperature-programmed oxidation test, the effects of extraneous moisture on the temperature increase rate of coal bodies and the emission characteristics of gaseous products during coal spontaneous combustion were studied. Moreover, combined with the characterization of thermal analysis and of pore structure test, the action the mechanism of extraneous moisture on the coal spontaneous combustion process was also explored. The experimental results indicated that the effect of the extraneous moisture content varied with the development of coal spontaneous combustion. In the slow oxidation stage, extraneous moisture played a physical inhibition role in the coal oxidation. In the accelerated oxidation stage, extraneous moisture exhibited a catalytic effect on the coal-oxygen reaction or directly participated in the reaction. After entering the rapid oxidation stage, a delayed effect appeared. When the coal temperature exceeded $180^{\circ} \mathrm{C}$, the spontaneous combustion characteristics of coals with different initial moisture contents gradually tended to achieved balance.
\end{abstract}

Keywords: coal spontaneous combustion; extraneous moisture; catalytic effect; delayed effect; balancing compensation

\section{Introduction}

During coal production, its spontaneous combustion adversely threatens the life safety of mining personnel and production safety of mining enterprises [1,2]. As one of the main factors that affect the oxidation of coal, moisture plays a key role in the spontaneous combustion of coal [3-6]. In terms of coal chemistry, original moisture in the coal matrix can be categorized into external moisture and internal moisture, according to its occurrence characteristics. The internal moisture in coal refers to the moisture originally present, which exists in an absorption or agglomeration mode in the capillary pores with a diameter of less than $10^{-5} \mathrm{~cm}$ in internal coal. External moisture refers to the originally 
present moisture that is adsorbed on the coal surface or within the capillary pores with a diameter of greater than $10^{-5} \mathrm{~cm}$. Generally, it is considered that there is a critical value between the external moisture and internal moisture, at which moisture has the greatest promoting effect on coal spontaneous combustion; above or below this threshold, the oxidation of coal will be inhibited to a certain extent $[7,8]$. From the perspective of disaster prevention and control, the moisture affecting the process of coal spontaneous combustion can be divided into the original occurrence moisture in the coal matrix and the extraneous moisture from the production process. The original occurrence moisture refers to the moisture contained in coal before the coal seam is exposed, and the extraneous moisture can be defined as the moisture brought into the coal body during its mining and processing after coal seam exposure due to the mining technology or safety prevention and control process. The redefinition of the type of moisture in a coal body from the perspective of disaster prevention and control is of great significance for the prevention and control of coal spontaneous combustion in coal mining and processing.

In recent years, numerous papers have mainly focused on the effect of the original moisture on the characteristics of the spontaneous coal combustion [9-11]. Some studies have revealed that external moisture exhibits a clear inhibition effect on coal oxidation; the lower the metamorphic grade of coal, the higher the moisture content, and the stronger the inhibition effect on coal oxidation $[12,13]$. For internal moisture, physical-state moisture exists on the coal particle surface, and there is a moisture layer on the surface, which reduces the porous structure and specific surface area and affects the oxygen diffusion; hence, the low-temperature oxidation of coal is inhibited [4,14]. On the other hand, chemical-bound moisture can participate in the formation and decomposition of a carbon-oxygen complex during the spontaneous combustion of coal [15-18]. Beamish et al. [19] investigated the effects of moisture content on the $\mathrm{R}_{70}$ self-heating rate contents and found there was a critical level of moisture content at approximately $40-50 \%$ of the moisture-holding capacity of the coal, above which the heat produced by oxidation was dissipated by moisture evaporation and coal self-heating was significantly delayed. Generally, a certain amount of moisture is thought to be involved in coal oxidation, and an optimal critical moisture content is present, although the critical value varies greatly with different coals [20-23]. Nevertheless, a sophisticated method for determining the critical moisture content has not been well-established thus far. Taking a wide view of the current studies, the mechanistic action of extraneous moisture on the spontaneous combustion of coal has not been considerably investigated; however, in practical production, the spontaneous combustion fire in coal mines is typically affected by extraneous moisture.

Extraneous moisture is involved in different coal production processes. For example, during the mining of high gas mines, holes should be drilled into the original coal without pressure relief for gas extraction. As the gas is extracted, moisture in coal is also extracted, leading to a lower content of moisture in coal. In the process of coal washing and processing, it is inevitable that extraneous water will be introduced; in the process of mining, surface water and groundwater leak along mining fissures to goaf, so that residual coal is in a state of water leaching [24,25]. Before stopping the mining process, pressurized moisture is injected into the coal layer through drills in advance, which leads to the infiltration of moisture into internal coal and forms a coal-gas-moisture three-phase system. This three-phase system changes the physiochemical and thermal properties and spontaneous characteristics of coal $[26,27]$. In the dust-proof process, internal and extraneous atomizing devices are used for atomizing on a stopping working surface and nearby areas, forming atomized moisture curtains to reduce a large amount of coal dusts produced by a coal cutting machine. This moisture in turn leads to an increase in the extraneous moisture content of coal. For coal mines damaged by moisture, moisture floods and soaks the coal, leading to an increase in the moisture content and affecting the spontaneous combustion characteristics of coal [27]. During mining of the coal layer, spontaneous combustion easily occurs, and protective actions such as preventive grouting must be adopted for goaf, outburst, and caving cavities to slightly increase the extraneous moisture in residual coal in goaf. This extraneous moisture not only separately affects the spontaneous combustion of coal, but also exhibits a combined action with other forms of moisture on the spontaneous combustion of coal. 
Therefore, it is crucial to examine the effect of extraneous moisture on the spontaneous combustion of coal with the aim of optimizing the design and application of the technological process.

In this study, long-flame coal with easy self-ignition and a low moisture content was selected as the experimental object. A suit of coal bodies with different extraneous moisture contents was prepared by soaking the long-flame coal. The moisture content in a coal body can be measured by an industrial analyzer, and the measured data is the sum of the extraneous moisture and the original occurrence moisture in the coal matrix. The moisture in a fresh coal sample is the original occurrence moisture in the coal. The difference in the moisture content between raw coal and coal bodies prepared from fresh coal by the soaking method can be regarded as the extraneous moisture content. During the test, the differences in spontaneous combustion characteristics between raw coal and prepared coals can be attributed to the effect of extraneous moisture. Using the temperature-programmed oxidation test, the effects of extraneous moisture on the temperature increase rate of coal bodies and the emission characteristics of gaseous products during coal spontaneous combustion were studied. Moreover, the action mechanism of extraneous moisture on the spontaneous combustion of coal was also discussed in combination with the characterization of thermal analysis and the pore structure.

\section{Experimental}

\subsection{Sample Collection and Preparation}

Long-flame coal from Wangiata mine in the Shendong mining area was used as the coal sample. The Wangjiata coal mine is situated in the eastern Shendong coalfield of China's Inner Mongolia Autonomous, as shown in Figure 1. The moisture content of the original coal sample is as low as $1.58 \%$. The proximate and ultimate analyses of the coals used in this study are shown in Table 1. One piece of fresh coal was removed from the surface oxidation layer, crushed under $\mathrm{N}_{2}$, and sieved to obtain a 0.180-0.150 mm coal sample, which was sealed for further use. Before the experiment, the coal sample was soaked in distilled moisture for 2 days, removed, and stored with a sealing procedure. Meanwhile, a certain amount of the coal sample was placed in the reactor, which was purged with $100 \mathrm{~mL} / \mathrm{min}$ of $\mathrm{N}_{2}$ at room temperature for dehydration. Coal samples for the experiments were obtained by the control of the drying time, and the moisture contents of the final eight coal samples were $20.00 \%$, $15.00 \%, 11.40 \%, 8.30 \%, 5.00 \%, 3.50 \%, 1.58 \%$ (original coal), and $0.00 \%$ (completely dried), respectively.

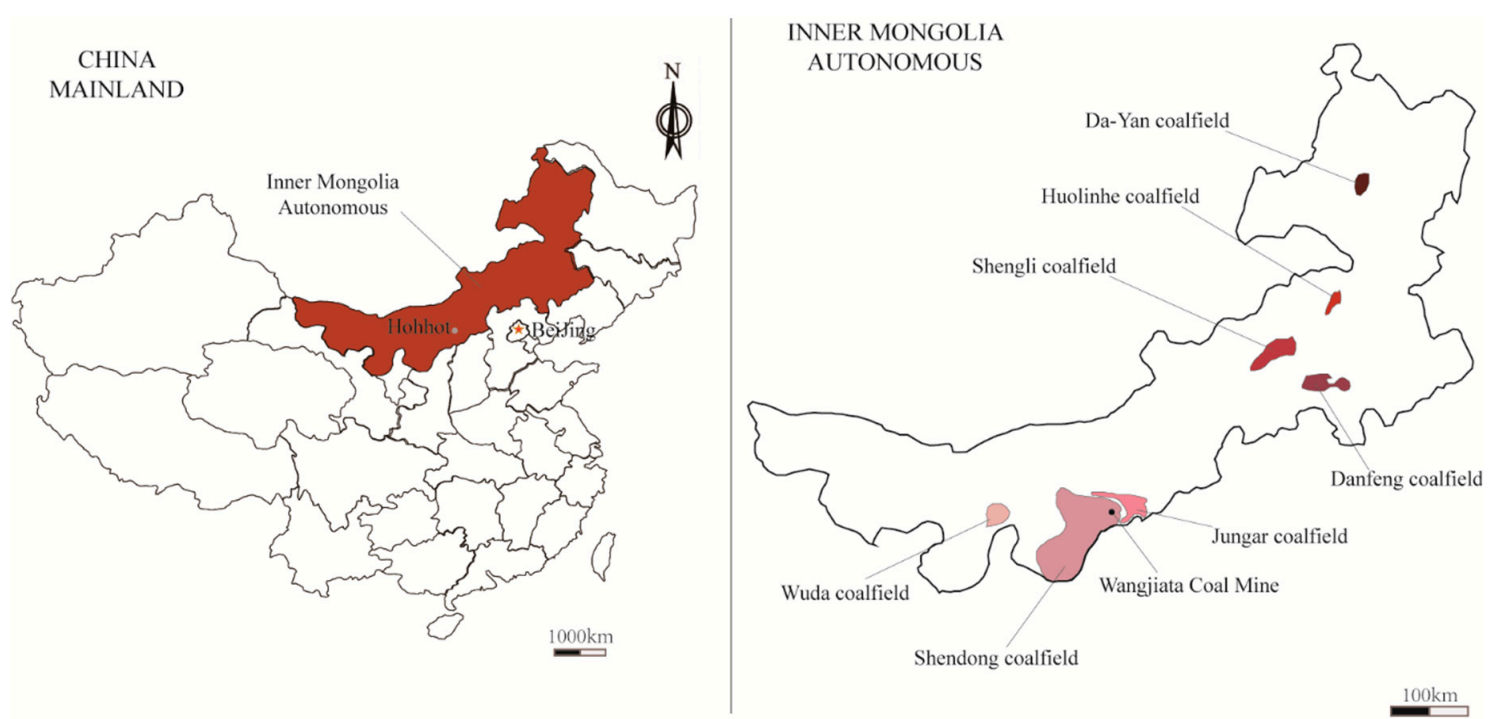

Figure 1. Location of the Wangjiata Coal Mine. 
Table 1. Proximate, ultimate, and sulfur form analyses of the raw coal used in the experiments.

\begin{tabular}{ccccccccccc}
\hline \multicolumn{3}{c}{ Proximate Analysis (wt\%) } & \multicolumn{4}{c}{ Ultimate Analysis (wt\%, daf) } & \multicolumn{3}{c}{ Sulfur Forms in Total Sulfur (wt\%) } \\
\hline $\mathrm{M}_{\mathrm{ad}}$ & $\mathrm{A}_{\mathrm{d}}$ & $\mathrm{V}_{\mathrm{daf}}$ & $\mathrm{C}$ & $\mathrm{H}$ & $\mathrm{O}^{*}$ & $\mathrm{~N}$ & $\mathrm{~S}$ & $\mathrm{~S}_{\mathrm{s}}$ & $\mathrm{S}_{\mathrm{p}}$ & $\mathrm{S}_{\mathrm{o}}{ }^{*}$ \\
\hline 10.15 & 4.25 & 31.26 & 76.26 & 4.56 & 16.56 & 1.80 & 0.82 & 5.6 & 77.9 & 16.5 \\
\hline
\end{tabular}

Note: ad, air dry basis; d, dry basis; daf, dry ash-free basis; $S_{s}$, sulfate sulfur; $S_{p}$, pyritic sulfur; $S_{o}$, organic sulfur; *, determined by difference.

\subsection{Temperature-Programmed Oxidation Experiments}

A temperature-programed oxidation experiment was carried out using the prepared coal samples with different moisture contents under the same experimental conditions. Figure 2 shows a schematic diagram of the experimental apparatus. During the experiment, $40.0 \mathrm{~g}$ of a coal sample was accurately weighted and placed in the reactor. The reactor was purged with $100 \mathrm{~mL} / \mathrm{min}$ of air, which was controlled by a mass flow meter. Then, the furnace temperature was increased from room temperature to $220^{\circ} \mathrm{C}$ at a heating rate of $1{ }^{\circ} \mathrm{C} / \mathrm{min}$ and controlled by a temperature-programmed chamber. The change in the temperature of the coal sample center to the inner temperature of the furnace was monitored during heating. Meanwhile, a GC-950 gas chromatography system was used to determine the concentrations of index gas during the heating oxidation of coal. For the same coal sample, the temperature-programmed oxidation experiment was repeated, and a certain amount of the coal sample was taken when the coal temperature reached $40,70,110,130,180$, and $220^{\circ} \mathrm{C}$ for specific surface area tests.

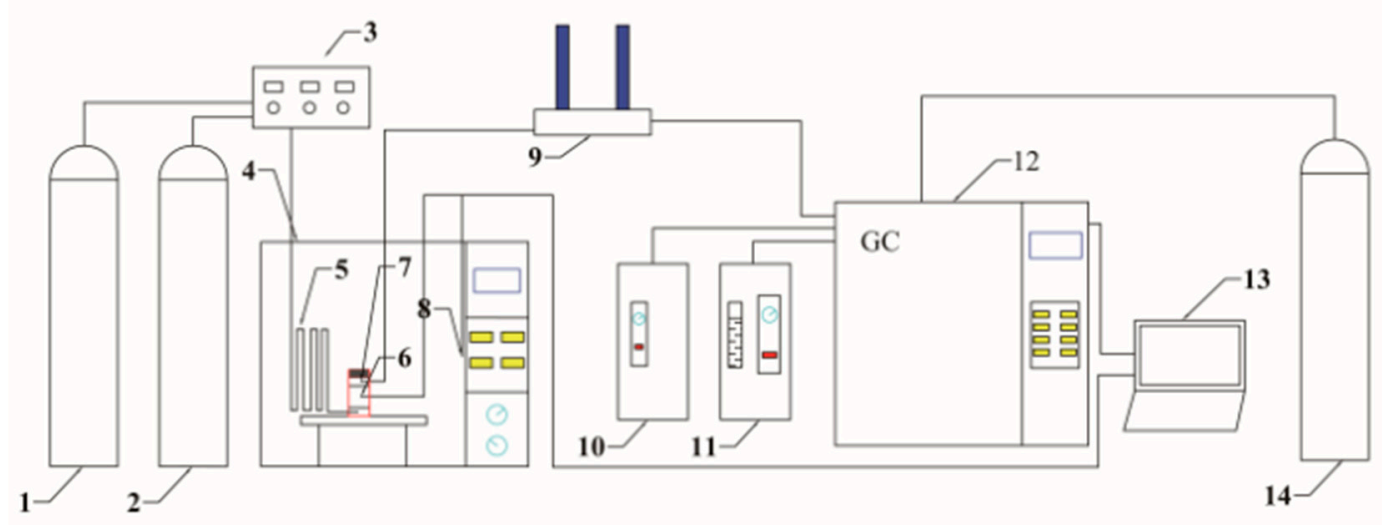

1.Nitrogen; 2. Air; 3. Mass flow meter; 4. Heating furnace; 5. Preheating gas circuit; 6. Thermocouple in coal sample; 7. Gas outlet; 8. Thermocouple in furnace; 9. Gas purifier; 10. Gir generator; 11. Hydrogen generator; 12. Gas chromatograph; 13. Computer; 14. Argon.

Figure 2. A schematic diagram of the experimental apparatus.

\subsection{Thermogravimetric Analysis (TGA) Experiment}

TGA was conducted on an STA-449-F5 thermal analyzer (Netzsch, Germany). First, $10.00 \mathrm{mg}$ of the coal sample was accurately weighted and placed in a crucible. Then, the coal sample was heated from room temperature to $300{ }^{\circ} \mathrm{C}$ at a heating rate of $1{ }^{\circ} \mathrm{C} / \mathrm{min}$, and the flow rate of dry air was $50 \mathrm{~mL} / \mathrm{min}$. Under the same experimental conditions, eight coal samples with different moisture contents were examined by TGA, and the change in the coal sample weight according to the change of temperature was monitored by the analyzer. 


\subsection{Specific Surface Area Analyzer}

The specific surface area was determined by a $3 \mathrm{H}-2000 \mathrm{PS} 4 \mathrm{~N}_{2}$ sorption analyzer purchased from Beishide Instrument (China) at a limiting vacuum of $4 \times 10^{-3} \mathrm{~Pa}$. The specific surface areas of the coal samples with different moisture contents prepared by the temperature-programmed method at different oxidation temperatures were examined. Traditionally, the removal of moisture and gas in material is the first step for the determination of the specific surface area using the $\mathrm{N}_{2}$ adsorption method under a vacuum condition. However, this process will inevitably remove all external moisture in coal, resulting in no way of determining the influence of moisture on the specific surface area of the coal structure. In order for capabilities to be useful, by consulting with an equipment engineer, the coal samples with different extraneous moisture contents could be directly determined using this equipment without the step of dehydration. The specific surface areas of the coal samples were calculated by the Brunauer-Emmett-Teller (BET) equation, according to the $\mathrm{N}_{2}$ adsorption value. Therefore, the change trend of the specific surface area of the coal samples with different moisture contents under different oxidation stages could be determined and analyzed.

\section{Results and Discussion}

\subsection{Temperature-Increase Rate of Coal}

Figure 3 shows the change trends of coal temperature during temperature-programmed oxidation. It can be seen that the mechanistic actions of the extraneous moisture varied with the increase of coal temperature and the process of coal spontaneous combustion can be divided into three stages. The first stage represented the coal temperature of $30-70{ }^{\circ} \mathrm{C}$, and the spontaneous combustion of coal was in the slow oxidation stage (Figure 3a). From this figure, the heating rate of coal samples decreased with the increase in the extraneous moisture content; that is, the coal samples with a high moisture content exhibited a slow heating rate, mainly related to the coagulation of extraneous moisture in the porous structure on the coal particle surface at this stage, thereby inhibiting the diffusion of oxygen and reducing the contact area between coal and oxygen. Meanwhile, the evaporation of extraneous moisture emitted partial heat and inhibited the oxidation of coal. Previous studies have revealed that with the increase in the moisture content of coal to some extent, an aqueous liquid film is formed on the coal surface, which can inhibit the contact between coal and oxygen and subsequently render an oxygen insulation effect $[4,14]$. At the same time, a majority of the heat released from coal at a low temperature can be consumed by the evaporation of moisture in coal. The heat absorbed by the evaporation of $1 \mathrm{~kg}$ of moisture is $2591.63 \mathrm{~kJ}$. With a $1 \%$ increase in the moisture content, $0.1 \%$ of the calorific value of coal can be reduced, which does not permit the accumulation of heat around coal; hence, the coal temperature does not increase, considerably prolonging the latency of the spontaneous combustion of coal.

The second stage was observed at $70-110^{\circ} \mathrm{C}$, and the spontaneous combustion of coal represented the accelerated oxidation stage. The effect of the extraneous moisture content on the heating rate of coal basically remained similar to the first stage. However, at a coal temperature of greater than $70{ }^{\circ} \mathrm{C}$, the heating rate of the coal sample with an initial moisture content of $3.50 \%$ was accelerated, which was even greater than the heating rates of the completely dried coal sample and the sample with a moisture content of $1.58 \%$ because a majority of the extraneous moisture in coal was removed at a temperature of greater than $70{ }^{\circ} \mathrm{C}$. The internal active sites started to be exposed, leading to an increase in the heating rate of the coal with a moisture content of $3.5 \%$, which was higher than those of the coals with $1.58 \%$ and $0.00 \%$ moisture contents. 


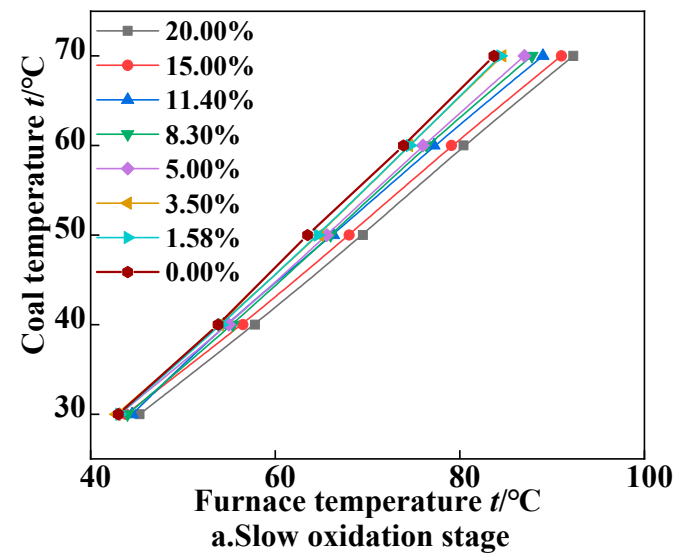

(a)

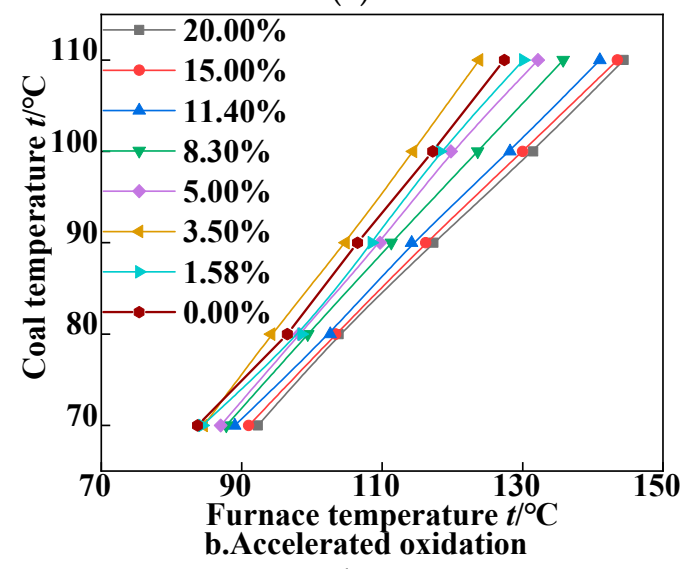

(b)

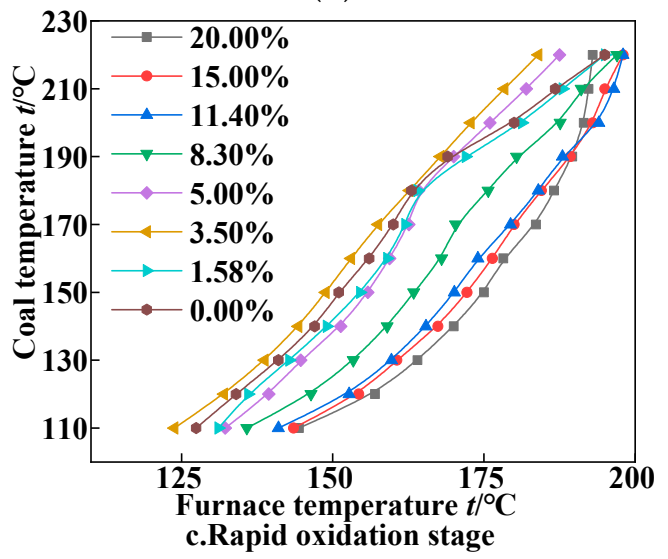

(c)

Figure 3. Change trends of the coal temperature during temperature programmed oxidation. 
The third stage was at the coal temperature range of $110-220^{\circ} \mathrm{C}$, and the spontaneous combustion of coal entered the rapid oxidation stage. Within the temperature range of $110-180{ }^{\circ} \mathrm{C}$, the overall heating rate of the coal sample was maintained so that it was basically similar to that at the second stage. When the coal temperature exceeded $180^{\circ} \mathrm{C}$, the heating rate of the coal with a high extraneous moisture content rapidly increased, indicating that the inhibition effect of moisture gradually disappears, and the promotion effect of moisture is observed at this stage. Compared with that of the coal with a high extraneous moisture content, the heating rate of coal with a low moisture content decreased, related to the formation of no new surface cracking during dehydration at the rapid oxidation stage. Meanwhile, partial active sites were consumed; thus, the heating rate decreases. With the further development of the spontaneous combustion of coal, the heating rate curves of the coals with different extraneous moisture contents gradually became similar and finally formed a balanced state.

The crossing-point temperature (CPT) refers to the temperature at which the coal body temperature exceeds the environmental temperature. From the change trend of the CPT value of coal samples with different extraneous moisture contents, the critical moisture content can be determined. The crossing-point temperature for analyzed coals can be obtained from temperature-programmed oxidation experiments. The crossing-point temperatures for coal samples with an extraneous moisture content of $20.00 \%, 15.00 \%, 11.40 \%, 8.30 \%, 5.00 \%, 3.50 \%, 1.58 \%$, and $0.00 \%$ are $190,188,185,170,158$, 148,158 , and $155^{\circ} \mathrm{C}$, respectively. The results are shown in Figure 4. It can be seen that the CPT first showed a decreasing trend with the decrease of the extraneous moisture content to $3.50 \%$, followed by an increasing trend with a further decrease of the moisture content. These results indicate that the critical moisture content is at around $3.5 \%$ with the lowest CPT of $148^{\circ} \mathrm{C}$. However, as for the current situation, the critical moisture content cannot be determined precisely.

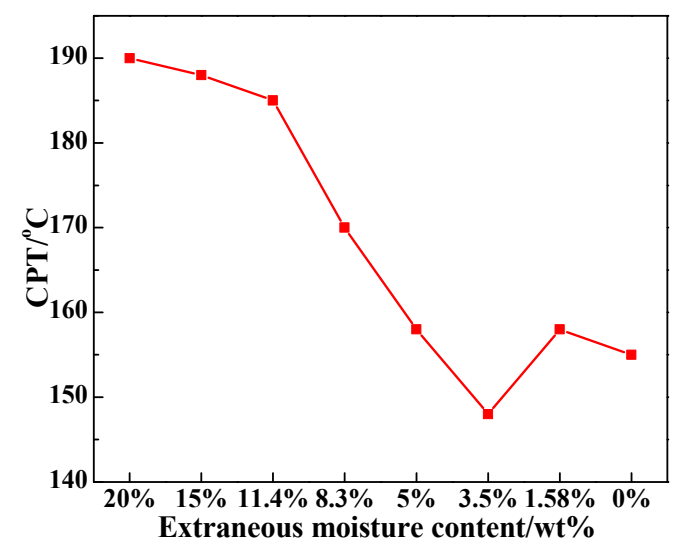

Figure 4. Crossing-point temperatures for coal samples with different extraneous moisture contents.

\subsection{Release Trends of $\mathrm{CO}$ and $\mathrm{CO}_{2}$}

Figure 5 shows the $\mathrm{CO}$ release trends of the coals with different extraneous moisture contents at different oxidation stages during temperature-programmed oxidation. According to the effect of extraneous moisture on the $\mathrm{CO}$ release from coal during temperature-programmed oxidation, the spontaneous combustion of coal can be divided into three stages. When the coal temperature was in the range of $30-70{ }^{\circ} \mathrm{C}$, the amount of released $\mathrm{CO}$ decreased with the increase in the extraneous moisture content of the coal because the extraneous moisture mainly inhibited the contact between coal and oxygen and reduced the spontaneous oxidation rate of coal, leading to a decrease in the CO release amount. In addition, with the increase in the extraneous moisture content, this physical inhibition effect continuously increased; thus, the $\mathrm{CO}$ release amount decreases with an increase in the extraneous moisture content. When the coal temperature was in the range of $70-110{ }^{\circ} \mathrm{C}$, partial moisture was still present in the coal samples, which inhibited the spontaneous combustion of coal, and the overall CO release was maintained so that it was similar to that in the first stage. However, when the coal sample 
with a moisture content of $3.5 \%$ was subjected to a temperature of greater than $90{ }^{\circ} \mathrm{C}$, the $\mathrm{CO}$ release amount rapidly increased, which was greater than that of the coal with a moisture content of $1.58 \%$ and the coal sample completely dried. This result was related to the fact that with the acceleration of the spontaneous combustion of coal, the moisture content reached a critical state in the coal with a moisture content of $3.50 \%$ at temperatures of greater than $90^{\circ} \mathrm{C}$. Under this condition, the physical inhibition effect disappeared, but the chemical promotion effect promoted the oxidation of coal, leading to an increase in the $\mathrm{CO}$ release amount. For the coal sample with a moisture content of greater than $3.50 \%$, the moisture in coal still exhibited an inhibition effect. For the coal with a moisture content of less than $3.50 \%$, the moisture basically evaporated completely, and the inhibition effect of extraneous moisture basically disappeared. The moisture content was extremely low and exhibited a chemical promotion effect. At a coal temperature of greater than $110^{\circ} \mathrm{C}$, the spontaneous combustion of coal entered the rapid oxidation stage, during which moisture in coal basically evaporated completely. The increase in the $\mathrm{CO}$ concentration for the coal with a low moisture content was slower than that for the coal with a high moisture content. For the coal with a high moisture content, the inhibition effect of moisture gradually disappeared, and the CO concentration increased with the moisture amount. Possibly due to the rapid dehydration of coal with a low moisture content, the active sites that formed at the early stage were consumed, new absorption sites were not formed, and the CO concentration increased slowly. On the contrary, the dehydration rate of coal with a high moisture content was slow, while the moisture-soluble substances within coal continuously precipitated and changed the internal structure of coal, leading to an increase in the specific surface area; the increased specific surface area was beneficial for the oxidation of coal.

Figure 6 shows the $\mathrm{CO}_{2}$ concentration release trend for the coal samples at different oxidation stages. From the figure, at the slow oxidation stage $\left(30-70{ }^{\circ} \mathrm{C}\right)$, the change tendency of the $\mathrm{CO}_{2}$ concentration was consistent with that of $\mathrm{CO}$. For the coal sample with a lower moisture content, the $\mathrm{CO}_{2}$ concentration was clearly greater than that for coal with a high moisture content, which was related to the low extraneous moisture amount. The moisture evaporation rate became rapid at this stage, and the coal-oxygen contact area was greater than that of the coal sample with a high moisture amount. At the rapid oxidation stage $\left(70-110{ }^{\circ} \mathrm{C}\right)$, the relationship between the $\mathrm{CO}_{2}$ concentration and extraneous moisture content changed, and the $\mathrm{CO}_{2}$ concentration increased with the increase of the extraneous moisture content. In particular, with the increase in the coal temperature, the promotion effect of the extraneous moisture on the formation of $\mathrm{CO}_{2}$ became increasingly clear, indicating that moisture is involved in the spontaneous combustion of coal and promotes the formation of $\mathrm{CO}_{2}$ precursor chemicals. The higher the moisture content is, the stronger the promotion effect is. At the rapid coal spontaneous oxidation stage, $\mathrm{CO}_{2}$ continued the release trend of the earlier stage. In particular, at a coal temperature of greater than $160^{\circ} \mathrm{C}$, the $\mathrm{CO}_{2}$ release concentration exponentially increased. At this stage, the extraneous moisture content of the coal samples was basically removed completely, and the inhibitory effect of moisture disappeared. The acceleration effect of temperature on the coal oxidation chemical reaction played the main role, and the combination reaction of coal with a high initial moisture content intensified and promoted the $\mathrm{CO}_{2}$ release concentration [28]. When the coal temperature reached $200{ }^{\circ} \mathrm{C}$, the formation of $\mathrm{CO}_{2}$ in the coal sample was no longer affected by the initial moisture content, and the difference in the $\mathrm{CO}_{2}$ release amounts among coals with different moisture contents gradually reduced and finally exhibited a similar tendency. 


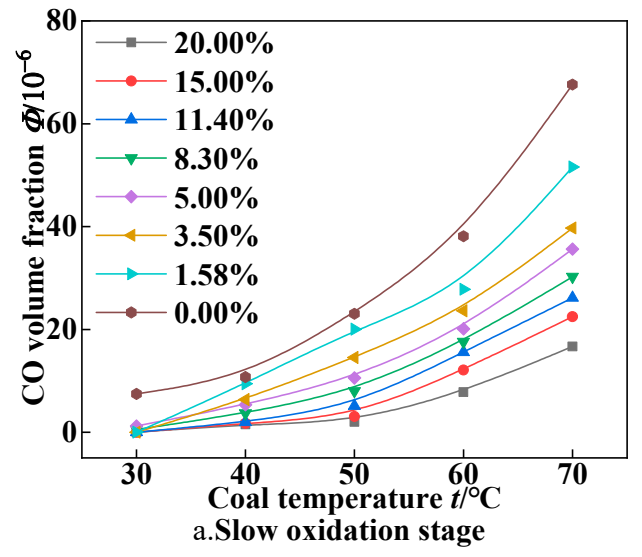

(a)

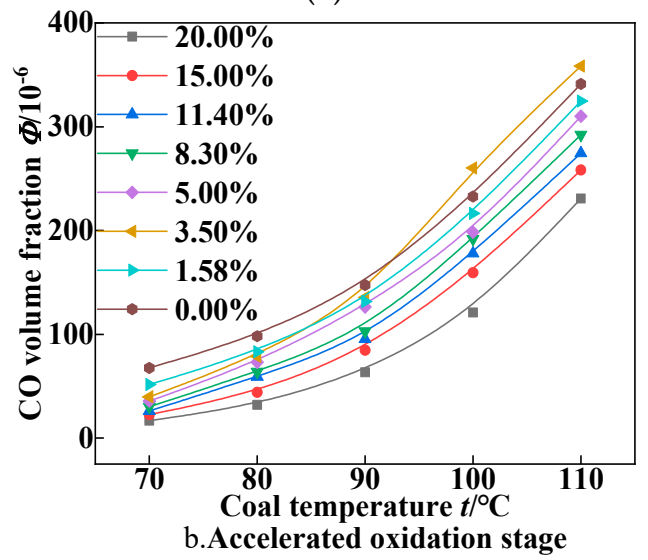

(b)

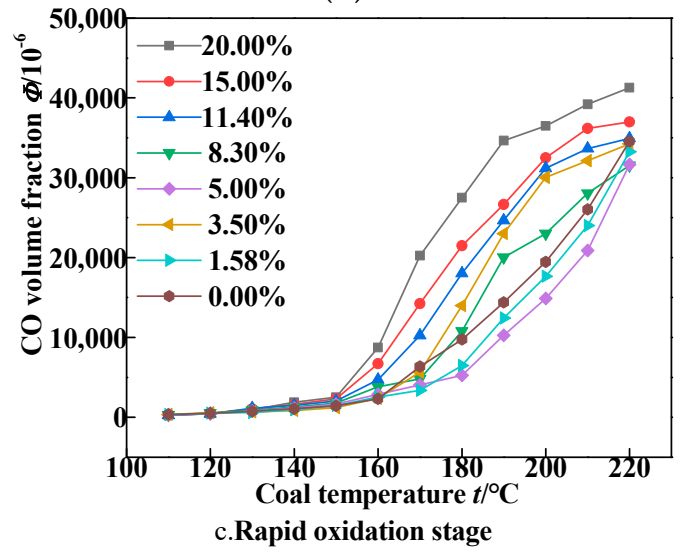

(c)

Figure 5. CO release trend of coal samples with different extraneous moisture contents during temperature-programmed oxidation. 


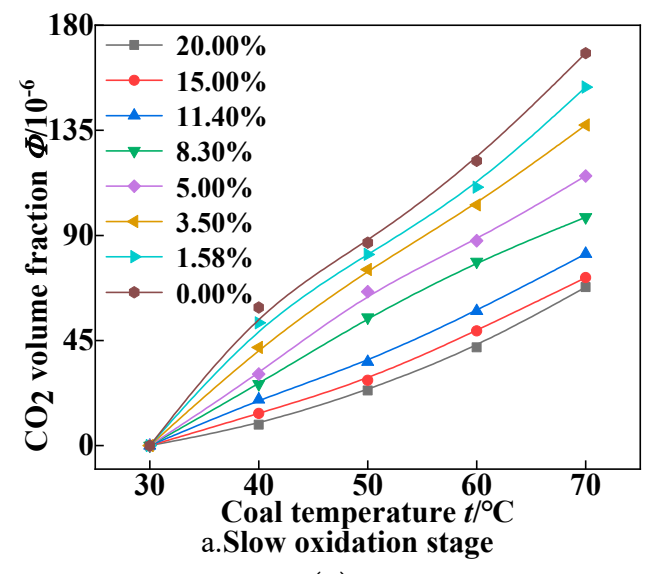

(a)

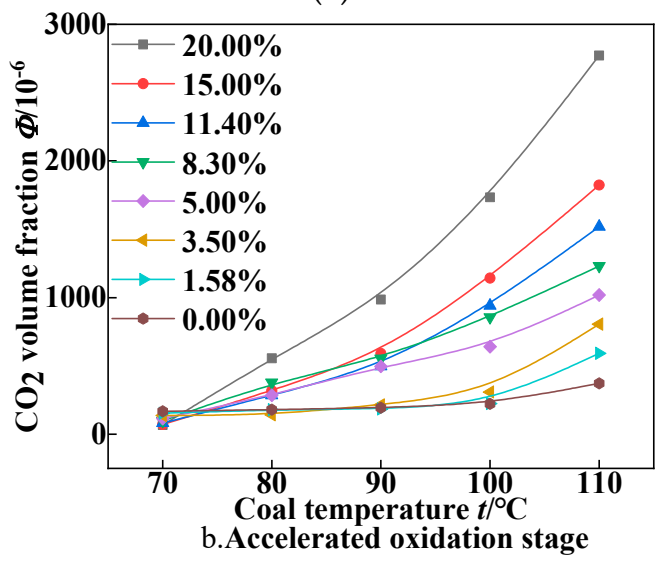

(b)

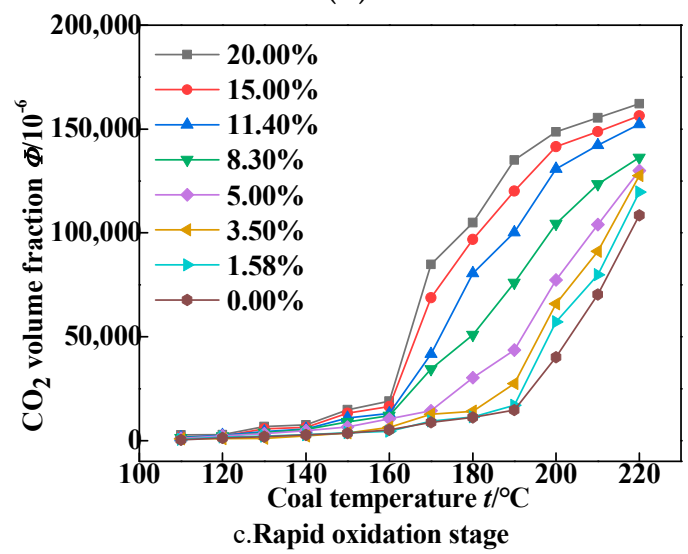

(c)

Figure 6. $\mathrm{CO}_{2}$ concentration release trend at different oxidation stages.

\subsection{Investigation of the Mechanistic Action}

The spontaneous combustion of coal is related to a series of multiple steps, which not only includes the evaporation of moisture and the formation of intermediate peroxides, but also includes the release of gaseous products. Meanwhile, there are several stages in the spontaneous combustion of coal, such as the slow oxidation stage, accelerated oxidation stage, and rapid oxidation stage. Moreover, the mechanistic actions of moisture at each stage are different. To further investigate the effect of extraneous moisture on the spontaneous combustion of coal, the mass and specific surface area of the coal with different moisture contents during temperature-programmed oxidation were determined by a thermal analyzer and specific surface area analyzer, respectively. In addition, the changes of coal 
mass and specific surface area are related to the temperature-increase rate of coal and release trend of $\mathrm{CO}_{2}$ and $\mathrm{CO}$, with the aim of revealing the mechanistic action of extraneous moisture during the spontaneous combustion of coal. Figure 7 shows the mass change curve of the coal samples with different moisture contents during oxidation. From the figure, with the progress of the spontaneous combustion of coal, the coal mass generally decreased first and then increased, and the extraneous moisture content considerably affected the coal sample mass.

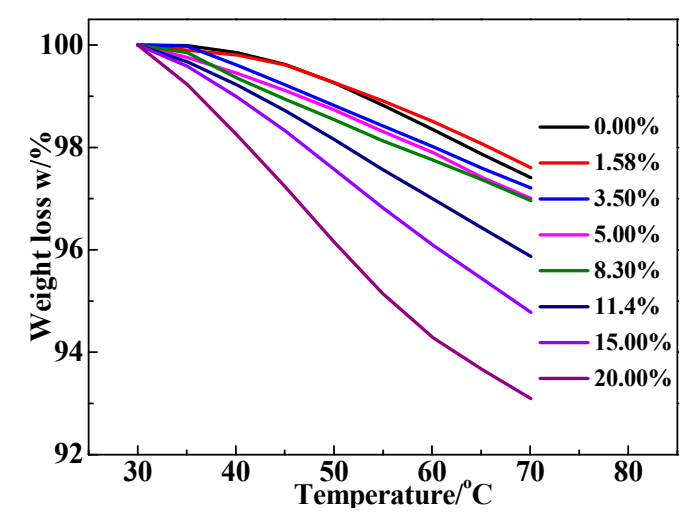

(a)

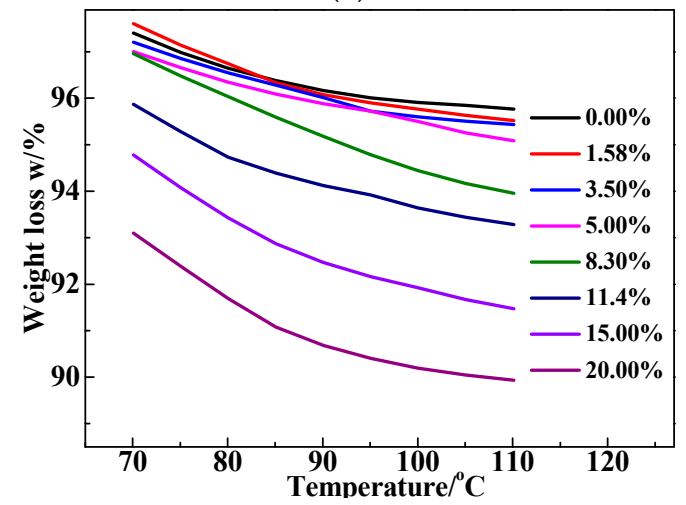

(b)

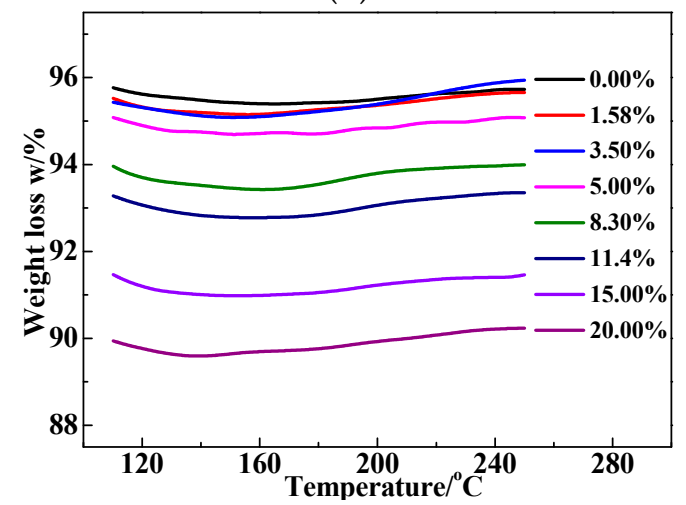

(c)

Figure 7. Change trends of coal mass at different stages during the heating and oxidation of coal with different water contents.

Table 2 summarizes the changes in the specific surface area of coals with different extraneous moisture contents during oxidation. From the data shown in Table 2, it can be seen that for different initial moisture contents of coal, the greater the moisture content in the coal body was, the smaller the specific surface area was. For the completely dry coal sample, its specific surface area in the whole heating process presented a slowly increasing trend. Correspondingly, for coal samples with certain moisture contents, their specific surface areas were increased first with the increase of coal temperature, 
and then a slightly decreasing trend was observed when the coal temperature was higher than $180^{\circ} \mathrm{C}$. This difference was due to the fact that there was no dehydration process for the completely dry coal sample in the process of coal spontaneous combustion, and the increase in its specific surface area was caused by the reaction between coal and oxygen. Therefore, a slow increasing trend was observed. The increase of the specific surface area for each moisture-bearing coal sample was caused by the dehydration process and the reaction of coal and oxygen. Therefore, the increasing trend of the specific surface area was faster, and the higher the moisture content of coal was, the faster the increase rate of the specific surface area was. Because each moisture-bearing coal sample exhibited a rapid increase in the specific surface area during heating, when the temperature of coal was higher than $180{ }^{\circ} \mathrm{C}$, coal structural collapse occurred, leading to a slight decrease in the specific surface area. Accordingly, the completely dry coal sample did not bear the dehydration process, and the specific surface area increased slowly. From Table 2, it can also be seen that the specific surface area of each moisture-bearing coal sample gradually became identical with the progress of coal spontaneous combustion.

Table 2. Specific surface area of the coals with different extraneous moisture contents during different temperature-programmed oxidation.

\begin{tabular}{ccccccc}
\hline \multirow{2}{*}{ Coal Samples } & \multicolumn{5}{c}{ Specific Surface Area of Coal Bodies $\left.\mathbf{( m}^{\mathbf{2}} / \mathbf{g}\right)$} \\
\cline { 2 - 7 } & $\mathbf{4 0}{ }^{\circ} \mathbf{C}$ & $\mathbf{7 0}^{\circ} \mathbf{C}$ & $\mathbf{1 1 0}{ }^{\circ} \mathbf{C}$ & $\mathbf{1 3 0}{ }^{\circ} \mathbf{C}$ & $\mathbf{1 8 0}^{\circ} \mathbf{C}$ & $\mathbf{2 2 0}^{\circ} \mathbf{C}$ \\
\hline $20.00 \%$ & 0.52 & 1.53 & 5.62 & 6.38 & 6.95 & 5.13 \\
$15.00 \%$ & 0.89 & 1.76 & 5.10 & 5.85 & 6.38 & 5.01 \\
$11.40 \%$ & 1.34 & 1.95 & 4.56 & 5.48 & 5.91 & 4.78 \\
$8.30 \%$ & 1.65 & 2.11 & 4.11 & 5.03 & 5.63 & 4.59 \\
$5.00 \%$ & 1.93 & 2.25 & 3.89 & 4.75 & 5.12 & 4.65 \\
$3.50 \%$ & 2.15 & 2.52 & 3.67 & 4.46 & 4.85 & 4.22 \\
$1.58 \%$ & 2.60 & 3.01 & 3.52 & 4.17 & 4.46 & 4.01 \\
$0.00 \%$ & 2.51 & 2.80 & 3.35 & 3.51 & 3.82 & 4.13 \\
\hline
\end{tabular}

As shown in Table 2, the extraneous moisture content considerably affected the specific surface area during the spontaneous combustion of coal. At a coal temperature below $70{ }^{\circ} \mathrm{C}$, the specific surface area of the coal sample decreased with the increase in the initial content of extraneous moisture. Conversely, at a coal temperature greater than $110^{\circ} \mathrm{C}$, the specific surface area of the coal sample increased with the increase of the initial content of extraneous moisture. Moreover, the specific surface area of coal exhibited the most increased amplitude in the temperature range of $70-110^{\circ} \mathrm{C}$. At the slow oxidation stage of coal spontaneous combustion $\left(30-70^{\circ} \mathrm{C}\right)$, physical absorption between coal and oxygen and moisture evaporation in coal were mainly observed. These two processes jointly determined the heating rate of coal spontaneous combustion and the change trend of coal mass, and both processes were affected by the moisture content in coal. Physical absorption between coal and oxygen mainly occurred through the absorption of oxygen by hydrophilic groups (mainly hydroxyl groups) on the coal surface and the gap structure. When the moisture content was greater than the critical value, the excess moisture formed a moisture film on the coal surface or gap, thereby inhibiting the transfer of oxygen within the inner coal particles and preventing contact and interaction between coal and oxygen. At this stage, with the increase in the coal temperature, the moisture within coal slowly evaporated and caused a reduction of the coal mass. Generally, the moisture evaporation rate and mass reduction for the coal with a high moisture content were greater than those for the coal with a low moisture content, which was consistent with the TGA curve trend shown in Figure 7. Coal with a moisture content of $1.58 \%$ exhibited the highest specific surface area, and the surface area rapidly decreased with the increase in the extraneous moisture content (Table 2). At a moisture content of $11.4 \%$, the specific surface area of the coal body was reduced by $50 \%$ compared with the coal sample with a moisture content of $1.58 \%$. With a further increase in the moisture content to $20.0 \%$, the specific surface area was only $18.3 \%$ of that of the coal with a moisture content of $1.58 \%$. Meanwhile, the decrease of coal mass due to moisture evaporation was far greater than the increase of coal mass observed by the 
physical absorption of oxygen at this stage; hence, the coal mass rapidly decreases with an increase in the extraneous moisture content (Figure 7). Therefore, at the slow oxidation stage, extraneous moisture exhibited a physical oxygen insulation effect on the spontaneous combustion of coal, and a reduction of the coal mass was introduced by moisture evaporation. Accordingly, the coal heating rate and the release of index gases were inhibited by extraneous moisture.

When the progress of coal spontaneous combustion entered the accelerated oxidation stage (70-110 $\left.{ }^{\circ} \mathrm{C}\right)$, chemical absorption between coal and oxygen, the formation and decomposition of intermediate complexes, and the moisture evaporation in coal were the main processes. Equation (1) shows the chemical absorption process between coal and oxygen. First, coal reacted with oxygen in air via chemical absorption to form a hydrogen peroxide complex. Moisture can reduce the activation energy for the chemical absorption between coal and oxygen and promote the complex reaction between coal and oxygen $[17,18]$. With the increase in the coal temperature, the formed hydrogen peroxide complex decomposed into ethers and hydroxyl free radicals (Equation (2)). These hydroxyl free radicals reacted with the active sites in coal to form alcohol compounds (Equation (3)), and these compounds further reacted to form aldehydes (Equation (4)). These aldehydes were either decomposed into $\mathrm{CO}$ (Equation (7)) or further oxidized to form acidic compounds under the effect of moisture (Equations (5) and (6)). During this process, moisture may participate in the reaction, and an appropriate amount of moisture was favorable for reactions 5 and 6 . With the further increase in the coal temperature, the acidic compounds formed in the reaction decomposed into $\mathrm{CO}_{2}$ (Reaction 8). At the rapid oxidation stage of coal spontaneous combustion, the complex reaction between coal and oxygen and the moisture evaporation in coal jointly affected the coal mass. The TGA curve shown in Figure 7 exhibited the joint effect of the two processes. The coal mass tended to decrease, and the weight loss rate of the coal with a higher moisture content was more rapid, indicating that the reduction of coal mass caused by the evaporation of extraneous moisture was far greater than the increase of coal mass caused by the complex reaction. Previous studies have shown that the subtraction TG spectrum could reflect the increase of the coal mass caused by the oxidation between coal and oxygen by eliminating the mass change caused by the moisture removal at the low-temperature oxidation stage. Moreover, when the coal temperature was just greater than $70^{\circ} \mathrm{C}$, the increase of the coal mass became slow. With a further increase in coal temperature, the increase rate of the coal mass rapidly increased $[29,30]$.

It can also be seen that at the accelerated oxidation stage $\left(70-110^{\circ} \mathrm{C}\right)$, the specific surface area of the moisture-containing coal rapidly increased with the increase of coal temperature, and the increase amount of the specific surface area increased with the initial content of extraneous moisture (Table 2). For example, the specific surface area of the coal with a moisture content of $20.00 \%$ at $110{ }^{\circ} \mathrm{C}$ was three times that at $70^{\circ} \mathrm{C}$, mainly because the original pores were exposed owing to the evaporation of a large amount of extraneous moisture. Meanwhile, rapid moisture evaporation also caused the formation of new cracks on the surface and inside of the coal body, inducing an increase of the coal specific surface area. Generally, at the accelerated oxidation stage of coal spontaneous combustion, moisture in the coal body plays a chemical catalytic role in the processes of chemical absorption between coal and oxygen and the formation and decomposition of the intermediate complex, and it may also participate in the complex reaction between coal and oxygen [17]. The moisture may mainly participate in the formation and decomposition of the peroxy-complex, which is conducive to the generation of $\mathrm{CO}_{2}[17,18]$. The higher the moisture content of the coal body is, the higher the amount of peroxide complexes formed, and the higher the $\mathrm{CO}_{2}$ release content is. However, it can also be seen that for the coal bodies with a low moisture content, such as the coal with a moisture content of $1.58 \%$ and the dried coal, the change in their specific surface area was opposite to that of the coal with a high moisture content, the specific surface area of which decreased with the increase in the temperature during the whole period. Additionally, the overall change trend was not significant. This is due to the fact that the evaporated moisture from the two coals was internal moisture at the accelerated oxidation stage. The removal of internal moisture caused the cracking and collapse of the internal capillary pores 
and surface porous structure of the coal particles, thereby decreasing the specific surface area [13]. This result is consistent with the change trends shown in Table 2.

When the status entered the rapid oxidation stage $\left(110-220^{\circ} \mathrm{C}\right)$, moisture was basically removed completely from the coal body. The process of coal spontaneous combustion mainly involves a chemical reaction between coal and oxygen, the formation and decomposition of intermediate complexes, and the release of gaseous products. At this stage, the promotion effect of temperature on the chemical reaction was significantly enhanced. With the increase in the coal temperature, the coal-oxygen chemical reaction rate rapidly increased, and the content of the formed oxygen-containing intermediate complex increased; accordingly, the release of index gases rapidly increased. From Table 2, it can be seen that during the first and second stages of coal spontaneous combustion, the higher the initial moisture content was, the greater the increase of the specific surface area was. For example, the specific surface area of the coal body with a moisture content of $20.00 \%$ at $110{ }^{\circ} \mathrm{C}$ was approximately one order of magnitude greater than that at $40^{\circ} \mathrm{C}$, while the specific surface area of the coal with a moisture content of $5.00 \%$ at $110{ }^{\circ} \mathrm{C}$ was two times that at $40^{\circ} \mathrm{C}$. This increase in the specific surface area accordingly led to an increase in the active sites of the coal samples. With the effect of temperature, these active sites rapidly reacted with oxygen; thus, the coal mass increased. In addition, the increase amount and increase rate of coal mass were consistent with the initial moisture content. The mass change tendency during the rapid oxidation stage is shown in Figure 7. It can be seen that the increase in the coal mass was greater in coals with a higher moisture content. For example, the mass of coal samples with moisture contents of $20.00 \%, 11.40 \%$, and $5.00 \%$ increased by $0.74 \%, 0.57 \%$, and $0.40 \%$, respectively. The change trends of the TGA curves and specific surface area both revealed that the extraneous moisture content has an indirect promotion effect on coal spontaneous combustion. That is, owing to the dehydration effect in the first and second stages of coal spontaneous combustion, the specific surface area increased, and the active sites in coal accordingly increased. With the increase in the oxidation temperature, these active sites rapidly reacted with oxygen and formed intermediate complexes; hence, a higher heating rate in the rapid oxidation stage of the coal with a higher extraneous moisture content was observed, as well as a higher mass increase and higher release of $\mathrm{CO}_{2}$ and $\mathrm{CO}$.

$$
\begin{aligned}
& \mathrm{R}+\mathrm{O}_{2} \stackrel{\mathrm{H}_{2} \mathrm{O}}{\rightarrow} \mathrm{R}-\mathrm{O}-\mathrm{O}+\mathrm{R}-\mathrm{H} \rightarrow \mathrm{R}-\mathrm{O}-\mathrm{OH} \\
& \mathrm{R}-\mathrm{O}-\mathrm{OH}+\mathrm{R} \cdot \stackrel{\Delta}{\rightarrow} \mathrm{R}-\mathrm{O}-\mathrm{R}+\mathrm{HO} \\
& \mathrm{R}+\mathrm{HO} \rightarrow \mathrm{R}-\mathrm{O}-\mathrm{H} \\
& \mathrm{R}^{\prime}-\mathrm{CHOH}-\mathrm{R}^{\prime \prime}+\mathrm{O}_{2} \rightarrow \mathrm{R}^{\prime}-\mathrm{CHO}+\mathrm{OH}^{\prime} \\
& \mathrm{R} \prime-\mathrm{CHO}+\mathrm{O}_{2}+\mathrm{H}_{2} \mathrm{O} \rightarrow \mathrm{R} \prime-\mathrm{CO} \cdots \mathrm{OH}_{2} \\
& \mathrm{R}^{\prime}-\mathrm{CO} \cdots \mathrm{OH}_{2}+\mathrm{R} \rightarrow \mathrm{R}^{\prime}-\mathrm{COOH}+\mathrm{R}-\mathrm{H} \\
& \mathrm{R} \prime-\mathrm{CHO} \stackrel{\Delta}{\rightarrow} \mathrm{CO}+\mathrm{R} \prime \mathrm{H} \\
& \mathrm{R} \prime-\mathrm{COOH} \stackrel{\Delta}{\rightarrow} \mathrm{CO}_{2}+\mathrm{R} / \mathrm{H}
\end{aligned}
$$

Based on the above findings, the effect of extraneous moisture on coal spontaneous combustion can be summarized, as shown in Figure 8. In Figure $8, W_{L}$ and $W_{H}$ represent the coal samples with relatively low and high extraneous moisture contents, respectively. At the slow oxidation stage $\left(30-70{ }^{\circ} \mathrm{C}\right)$, the extraneous moisture content mainly physically inhibits coal oxidation. Owing to a large amount of extraneous moisture being absorbed on the coal body, extraneous moisture blocks the contact between oxygen and the coal particle surface and the internal porous structure. Meanwhile, as the water is removed, it will take away partial reaction heat, thus inhibiting the coal reaction. The higher the moisture content of coal is, the higher the inhibition effect is. At $70-110^{\circ} \mathrm{C}$, the moisture plays a catalytic role in the coal-oxygen reaction or directly participates in the reaction. The reaction intensity of the coal 
with a higher moisture content gradually exceeds that of the coal with a lower moisture content, which is related to the formation of a peroxide complex. At $110-180^{\circ} \mathrm{C}$, the reaction intensity continuously increases, and the effect of moisture on the coal-oxygen reaction mainly manifests the changes in the specific surface area and porous structure. In the first two oxidation stages, the evaporation of a large amount of extraneous moisture leads to an increase of surface cracking in coal particles, and the internal structure blocked by moisture is opened. Therefore, compared to the coal with a low moisture content, the higher the moisture content, the more active points will be generated and the stronger the reaction intensity will be. After the coals undergo the first three stages at a temperature of more than $180^{\circ} \mathrm{C}$, the moisture content has basically been removed completely. The influence of moisture on the coal-oxygen reaction becomes weaker, and the reaction intensities of the coals with different initial contents of extraneous moisture gradually incline to be the same, achieving balancing compensation.

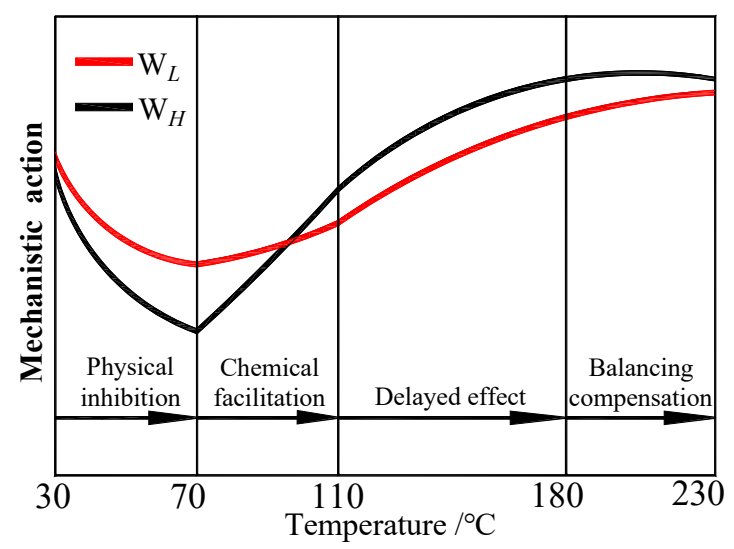

Figure 8. Action mechanism of external water involved in the oxidation reaction.

\section{Conclusions}

The effect of extraneous moisture on coal spontaneous combustion switches at different stages, mainly related to the fact that the mechanistic action of the extraneous moisture content on coal spontaneous combustion changes with the reaction stage. In the slow oxidation stage $\left(30-70{ }^{\circ} \mathrm{C}\right)$, the heating rate of the coal body and the release rate of $\mathrm{CO}$ and $\mathrm{CO}_{2}$ are reduced with an increase in the extraneous moisture content. In the rapid oxidation stage $\left(70-110^{\circ} \mathrm{C}\right)$, the heating rate of the coal body and increasing tendency of $\mathrm{CO}$ release remain unchanged, while the amount of $\mathrm{CO}_{2}$ release increases with the moisture content due to the participation of moisture in the reaction. In the rapid oxidation stage $\left(110-180^{\circ} \mathrm{C}\right)$, the increase intensity of CO release from the coal with a low moisture content is lower than that from coal with a high moisture content; meanwhile, for coal with a high moisture content, the inhibition effect gradually disappears, and the CO release amount increases with the increase of the moisture content. Based on the experimental findings, the effect of extraneous moisture on coal spontaneous combustion can be summarized. In the slow oxidation stage, the extraneous moisture has a physical inhibition effect on coal spontaneous combustion, mainly by isolating the contact reaction of coal and oxygen. In the accelerated oxidation stage, the moisture may be involved in the process of the coal-oxygen reaction, promoting the rate of coal self-heating. After entering the rapid oxidation stage, due to the large amount of extraneous moisture that is removed during the first and second stages, the pore structure and specific surface area of the coal body are increased; the higher the extraneous moisture content in the coal body, the more active points will be generated, and the extraneous moisture presents an indirect promoting effect. When the coal body temperature is above $180^{\circ} \mathrm{C}$, the spontaneous combustion characteristics of coals with different initial external moisture contents gradually tend to be consistent, achieving balancing compensation. 
Author Contributions: Conceptualization, Y.Z. and Y.W.; validation, C.Z., X.Z., and J.W.; formal analysis, X.Z.; investigation, J.W.; writing—original draft preparation, X.Z. and Y.W.; writing-review and editing, Y.Z.; supervision, J.W. All authors have read and agreed to the published version of the manuscript.

Funding: The authors gratefully acknowledge the financial support of the National Science Foundation for Young Scientists of China (51704207), Science and Technology Innovation Project in Higher Education Institutions of Shanxi Province (2017140), Excellent Talents Science and Technology Innovation Project of Shanxi Province (201705D211004), Shanxi Province Key R\&D Program (International Cooperation) Project (201803D421105), Shanxi Province Applied Basic Research Program Project (201901D111073).

Conflicts of Interest: The authors declare no conflict of interest. The founding sponsors had no role in the design of the study; in the collection, analyses, or interpretation of data; in the writing of the manuscript; and in the decision to publish the results.

\section{References}

1. Song, Z.; Kuenzer, C. Coal fires in China over the last decade: A comprehensive review. Int. J. Coal Geol. 2014, 133, 72-99. [CrossRef]

2. Liang, Y.; Zhang, J.; Wang, L.; Luo, H.; Ren, T. Forecasting spontaneous combustion of coal in underground coal mines by index gases: A review. J. Loss Prev. Process. Ind. 2019, 57, 208-222. [CrossRef]

3. Arisoy, A.; Beamish, B. Mutual effects of pyrite and moisture on coal self-heating rates and reaction rate data for pyrite oxidation. Fuel 2015, 139, 107-114. [CrossRef]

4. Miura, K. Adsorption of water vapor from ambient atmosphere onto coal fines leading to spontaneous heating of coal stockpile. Energy Fuels 2016, 30, 219-229. [CrossRef]

5. Song, S.; Qin, B.; Xin, H.; Qin, X.; Chen, K. Exploring effect of water immersion on the structure and low-temperature oxidation of coal: A case study of Shendong long flame coal, China. Fuel 2018, 234, $732-737$. [CrossRef]

6. Wang, G.; Wang, Y.; Sun, L.; Song, X.; Liu, Q.; Xu, H.; Du, W. Study on the low-temperature oxidation law in the co-mining face of coal and oil shale in a goaf-A case study in the Liangjia coal mine, China. Energies 2018, 11, 174. [CrossRef]

7. Vance, W.E.; Chen, X.D.; Scott, S.C. The rate of temperature rise of a subbituminous coal during spontaneous combustion in an adiabatic device: The effect of moisture content and drying methods. Combust. Flame 1996, 106, 261-270. [CrossRef]

8. Xu, T.; Wang, D.M.; He, Q.L. The study of the critical moisture content at which coal has the most high tendency to spontaneous combustion. Int. J. Coal Prep. Util. 2013, 33, 117-127. [CrossRef]

9. Fan, J.; Wang, G.; Zhang, J. Study on spontaneous combustion tendency of coals with deferent metamorphic grade at low moisture content based on TPO-DSC. Energies 2019, 12, 3890. [CrossRef]

10. Wang, H.; Dlugogorski, B.Z.; Kennedy, E.M. Role of inherent water in low-temperature oxidation of coal. Combust. Sci. Technol. 2003, 175, 253-270. [CrossRef]

11. Zhang, K.; You, C. Effect of upgraded lignite product water content on the propensity for spontaneous ignition. Energy Fuels 2013, 27, 20-26. [CrossRef]

12. Arisoy, A.; Beamish, B.; Yoruk, B. Moisture moderation during coal self-heating. Fuel 2017, 210, 352-358. [CrossRef]

13. Yu, J.; Tahmasebi, A.; Han, Y.; Yin, F.; Li, X. A review on water in low rank coals: The existence, interaction with coal structure and effects on coal utilization. Fuel Process. Technol. 2013, 106, 9-20. [CrossRef]

14. Kus, J.; Misz-Kennan, M. Coal weathering and laboratory (artificial) coal oxidation. Int. J. Coal Geol. 2017, 171, 12-36. [CrossRef]

15. Clemens, A.H.; Matheson, T.W. The role of moisture in the self-heating of low-rank coals. Fuel 1996, 75, 891-895. [CrossRef]

16. Li, Z.; Kong, B.; Wei, A.; Yang, Y.; Zhou, Y.; Zhang, L. Free radical reaction characteristics of coal low-temperature oxidation and its inhibition method. Environ. Sci. Pollut. Res. 2016, 23, 23593-23605. [CrossRef]

17. Qu, Z.; Sun, F.; Gao, J.; Pei, T.; Qie, Z.; Wang, L.; Pi, X.; Zhao, G.; Wu, S. A new insight into the role of coal adsorbed water in low-temperature oxidation: Enhanced.OH radical generation. Combust. Flame 2019, 208, 27-36. [CrossRef] 
18. Wang, H.; Dlugogorski, B.Z.; Kennedy, E.M. Coal oxidation at low temperatures: Oxygen consumption, oxidation products, reaction mechanism and kinetic modeling. Prog. Energy Combust. Sci. 2003, 29, 487-513. [CrossRef]

19. Beamish, B.B.; Garth, F.; Hamilton, R. Effect of moisture content on the $\mathrm{R}_{70}$ self-heating rate of Callide coal. Int. J. Coal Geol. 2005, 64, 133-138. [CrossRef]

20. Chen, X.D.; Stott, J.B. The effect of moisture content on the oxidation rate of coal during near-equilibrium drying and wetting at $50{ }^{\circ} \mathrm{C}$. Fuel 1993, 72, 787-792. [CrossRef]

21. Li, Y.; Zhao, H.; Song, Q.; Wang, X.; Shu, X. Influence of critical moisture content in lignite dried by two methods on its physicochemical properties during oxidation at low temperature. Fuel 2018, 211, 27-37. [CrossRef]

22. Zhang, Z.; Yan, K. Molecular dynamics simulation of oxygen diffusion in dry and water-containing brown coal. Mol. Phys. 2011, 109, 2367-2374. [CrossRef]

23. Zhao, H.; Yu, J.; Liu, J.; Tahmasebi, A. Experimental study on the self-heating characteristics of Indonesian lignite during low temperature oxidation. Fuel 2015, 150, 55-63. [CrossRef]

24. Tang, Y.; Xue, S. Influence of long-term water immersion on spontaneous combustion characteristics of Bulianta bituminous coal. Int. J. Oil Gas Coal Technol. 2017, 14, 398-411. [CrossRef]

25. Yang, Y.; Li, Z.; Si, L.; Gu, F.; Zhou, Y.; Qi, Q.; Sun, X. Study governing the impact of long-term water immersion on coal spontaneous ignition. Arab. J. Sci. Eng. 2016, 42, 1-11. [CrossRef]

26. Wang, X.; Luo, Y.; Vieira, B. Experimental technique and modeling for evaluating heat of rewetting effect on coals propensity of spontaneous combustion based on adiabatic oxidation method. Int. J. Coal Geol. 2018, 187, 1-10. [CrossRef]

27. Zhong, X.; Kan, L.; Xin, H.; Qin, B.; Dou, G. Thermal effects and active group dierentiation of low-rank coal during low-temperature oxidation under vacuum drying after water immersion. Fuel 2019, 236, 1204-1212. [CrossRef]

28. Soria, M.A.; Rocha, C.; Tosti, S.M.A.; Madeira, L.M. $\mathrm{CO}_{\mathrm{x}}$ free hydrogen production through water-gas shift reaction in different hybrid multifunctional reactors. Chem. Eng. J. 2019, 356, 727-736. [CrossRef]

29. Li, Z.; Zhang, Y.; Jing, X.; Zhang, Y.; Chang, L. Insight into the intrinsic reaction of brown coal oxidation at low temperature: Differential scanning calorimetry study. Fuel Process. Technol. 2016, 147, 64-70. [CrossRef]

30. Zhang, Y.; Wang, J.; Xue, S.; Wu, Y.; Chang, L.; Li, Z. Evaluation of the susceptibility of coal to spontaneous combustion by a TG profile subtraction method. Korean J. Chem. Eng. 2016, 33, 862-872. [CrossRef] 